\title{
An Improved Sideband Current Harmonic Model of Interior PMSM Drive by Considering Magnetic Saturation and Cross-Coupling Effects
}

\begin{abstract}
The sideband current harmonics, as parasitic characteristics in permanent magnet synchronous machine drives with space vector pulsewidth modulation technique, will increase the corresponding electromagnetic loss, torque ripple, vibration, and acoustic noises. Therefore, fast yet accurate evaluation of the resultant sideband current harmonic components is of particular importance during the design stage of the drive system. However, the inevitable magnetic saturation and cross-coupling effects in interior permanent magnet synchronous machine drives would have a significant impact on the current components, while the existing analytical sideband current harmonic model neglects those effects. This paper introduces a significant improvement on the analytical model by taking into account these effects with corresponding nonlinear factors. Experimental results are carried out to underpin the accuracy improvements of the predictions from the proposed model over the existing analytical one. The proposed model can offer a very detailed and insightful revelation of impacts of the magnetic saturation and cross-coupling effects on the corresponding sideband current harmonics.
\end{abstract}

Index Terms-Bessel function, cross-coupling effect, interior permanent magnet synchronous machine, Magnetic saturation, sideband harmonic, space vector pulsewidth modulation.

\section{NOMENCLATURE}

$\delta \quad$ The torque angle.

$J_{k} \quad$ The $k^{t h}$-order Bessel function.

$L_{d} \quad$ The $d$-axis incremental inductance.

$L_{q} \quad$ The $q$-axis incremental inductance.

$M_{d q} \quad$ The $d-q$ axes mutual incremental inductance.

$M \quad$ The modulation ratio.

$i_{d} \quad$ The $d$-axis component of stator current vector.

$i_{q} \quad$ The $q$-axis component of stator current vector.

$\sigma_{M} \quad$ Cross-coupling coefficient.

$U_{d c} \quad$ Direct current bus voltage.

$u_{d} \quad$ The $d$-axis component of stator voltage vector.

$u_{q} \quad$ The $q$-axis component of stator voltage vector.

$\omega_{e} \quad$ Modulation angular speed.

$\omega_{s} \quad$ Carrier angular speed.

\section{INTRODUCTION}

$\mathbf{N}$ OWADAYS, the immense advancements of high-strength permanent magnet (PM) material, high-efficiency power electronic device, and high-performance digital signal processor, have been contributing in building up the momentum of developing exquisite variable-frequency permanent magnet synchronous machine (PMSM) drives for various existing and emerging applications [1]-[3]. Meanwhile, the space vector pulsewidth modulation (SVPWM) technique is widely implemented in such PMSM drive systems in order to achieve great dynamic performances. However, sideband voltage and current harmonic components, whose frequencies are generally located nearby the carrier frequency and its multiples, will be inevitably induced during the intrinsic switching processes engendered by the SVPWM technique. These undesirable sideband harmonic components will not only increase the electromagnetic losses [4]-[6] including winding resistive loss, iron core loss, and PM eddy current loss, but can also deteriorate the characteristics of electromagnetic torque [7], [8], vibration, and acoustic noise [9], [10] in the drive systems. Consequently, fast yet accurate analytical evaluations of such sideband harmonic components are of particular importance during the design stage of the drive system. These analytical studies have been mainly concentrated on the derivation of sideband voltage harmonics by using various methods [11][14], while the analytical derivations of the sideband current harmonic related coefficients, such as harmonic distortion rate [15], peak ripple value [16], and flux harmonic distortion factor [17], [18] have also been developed in the literature. Meanwhile, various methods such as special switching sequence [19], [20], multilevel inverter topologies [21], [22], and random pulse width [23], have been introduced to mitigate the sideband harmonic components in the drive systems with SVPWM technique.

Not until quite recently have there been particular investigations on full direct analytical developments of sideband voltage and current harmonic components in the induction machine [24] and PMSM [25] drive systems with SVPWM technique. However, these analytical derivations of the sideband current harmonic components are all based on the assumption of no magnetic saturation in the corresponding electric machines. On the other hand, interior PM (IPM) configuration is normally preferred for PMSM to increase both flux concentration and rotor saliency so that the corresponding PM induction and reluctance torques can be boosted and harnessed to further improve the overall torque performance [26]. The inherent features of IPM structure and nonlinearity of ferromagnetic material will inevitably bring about magnetic saturation and cross-coupling effects in the machine, especially under large load conditions. These unavoidable effects will impose the nonlinear dependency of machine inductance on the armature current. It amounts to that the mutual inductance between $d$ and $q$-axes will appear, and all the synchronous inductances are no longer constants and depend on the magnetic state of the machine [27], [28]. Such nonlinear characteristics of the inductances will have a significant impact on not only the low order current harmonics but also the high order sideband ones in interior PMSM drives, which are neglected by the existing analytical sideband current harmonic model [25]. 
It can be expected that the direct implement of the existing analytical sideband current harmonic model can potentially introduce large errors to the corresponding predictions in interior PMSM drives with load conditions. Consequently, this paper proposes an improved sideband current harmonic model by incorporating the nonlinear factors so that the magnetic saturation and cross-coupling effects in interior PMSMs are taken into considerations. Besides the common influence factors, the proposed model can offer a very detailed and insightful revelation of impacts of the magnetic saturation and cross-coupling effects on the corresponding sideband current harmonics. Section II introduces the analytical expressions of main sideband voltage harmonic components nearby the first and second carrier frequency induced by symmetrical sampled SVPWM technique in rotor synchronous frame. In Section III, the improved analytical model of the corresponding sideband current harmonic components are derived in both the rotor synchronous and stator stationary frames by considering the magnetic saturation and cross-coupling effects. Section IV is devoted to the validations on accuracy improvements of the proposed method over the existing one by experimental results from a prototype interior PMSM with two different control strategies, followed by the concluding remarks in Section V.

\section{Analytical Expressions of Sideband Voltage HARMONICS IN THE ROTOR SYNCHRONOUS FRAME}

The analytical derivations of the sideband voltage harmonics induced by common three-phase two-level voltage source inverter (VSI) with SVPWM technique have been introduced in detail with Fourier series analysis and coordinate transformation [24], [25]. The resultant main sideband voltage harmonic components, whose frequencies are located nearby the first and second carrier frequency, can be expressed in the rotor synchronous frame as

$$
\begin{gathered}
\left\{\begin{array}{l}
u_{d_{-}\left(\omega_{s} \pm 3 \omega_{e}\right)}=0.5 U_{d c} U_{d \_13} \cos \left(\left(\omega_{s} \pm 3 \omega_{e}\right) t \pm \varphi_{d \_13}\right) \\
u_{q_{-}\left(\omega_{s} \pm 3 \omega_{e}\right)}= \pm 0.5 U_{d c} U_{q_{-} 13} \sin \left(\left(\omega_{s} \pm 3 \omega_{e}\right) t \pm \varphi_{q_{-} 13}\right)
\end{array}\right. \\
\left\{\begin{array}{l}
u_{d \_\left(2 \omega_{s}\right)}=-U_{d c} C_{21} \sin \delta \cos \left(2 \omega_{s} t\right) \\
u_{q_{-}\left(2 \omega_{s}\right)}=U_{d c} C_{21} \cos \delta \cos \left(2 \omega_{s} t\right)
\end{array}\right. \\
\left\{\begin{array}{l}
u_{d_{-}\left(2 \omega_{s} \pm 6 \omega_{e}\right)}=0.5 U_{d c} U_{d \_26} \cos \left(\left(2 \omega_{s} \pm 6 \omega_{e}\right) t \pm \varphi_{d \_26}\right) \\
u_{q_{-}\left(2 \omega_{s} \pm 6 \omega_{e}\right)}= \pm 0.5 U_{d c} U_{q_{-} 26} \sin \left(\left(2 \omega_{s} \pm 6 \omega_{e}\right) t \pm \varphi_{q_{-} 26}\right)
\end{array}\right.
\end{gathered}
$$

where

$$
\begin{aligned}
& \left\{\begin{array}{l}
U_{d \_13}=\sqrt{C_{12}^{2}+C_{14}^{2}+2 C_{12} C_{14} \cos (2 \delta)} \\
U_{q_{\_} 13}=\sqrt{C_{12}^{2}+C_{14}^{2}-2 C_{12} C_{14} \cos (2 \delta)}
\end{array}\right. \\
& \left\{\begin{array}{l}
U_{d \_26}=\sqrt{C_{25}^{2}+C_{27}^{2}+2 C_{25} C_{25} \cos (2 \delta)} \\
U_{q_{-} 26}=\sqrt{C_{25}^{2}+C_{27}^{2}-2 C_{25} C_{25} \cos (2 \delta)}
\end{array}\right.
\end{aligned}
$$

and the initial phase $\varphi_{d \_13}, \varphi_{q_{-} 13}, \varphi_{d \_26}$, and $\varphi_{q_{-} \_6}$ in equations (1) and (3) can be expressed as

$$
\begin{gathered}
\left\{\begin{array}{l}
\varphi_{d \_13}=\pi+\arctan \frac{\left(C_{14}-C_{12}\right) \tan \delta}{\left(C_{14}+C_{12}\right)} \\
\varphi_{q \_13}=\arctan \frac{\left(C_{14}+C_{12}\right) \tan \delta}{\left(C_{14}-C_{12}\right)}
\end{array}\right. \\
\left\{\begin{array}{l}
\varphi_{d \_26}=\arctan \frac{\left(C_{25}+C_{27}\right) \cot \delta}{\left(C_{25}-C_{27}\right)} \\
\varphi_{q_{-} 26}=\pi+\arctan \frac{\left(C_{25}-C_{27}\right) \cot \delta}{\left(C_{25}+C_{27}\right)}
\end{array}\right.
\end{gathered}
$$

The detailed analytical expressions of coefficients $C_{21}, C_{12}$, $C_{14}, C_{25}$, and $C_{27}$ are provided in the Appendix. Hence, those major sideband voltage harmonic components can be promptly evaluated by using the direct current bus voltage and corresponding SVPWM modulation ratio.

\section{Improved ANALyticAl Sideband CURRENT HARMONIC MODELING}

Based on the those sideband voltage harmonic components, the analytical models of corresponding sideband current harmonics in PMSM drive systems have been obtained [25]. However, these models are merely valid for the surface mounted PMSM drive systems or the interior PMSM ones with relatively light load conditions as they are developed based on the independency of machine inductance on the armature current. However, the armature inductances are highly influenced by the inevitable magnetic saturation in interior PMSM especially under heavy load conditions. Moreover, the cross-coupling effects will occur under extreme saturation conditions and result in an indispensable mutual inductance between $d$ - and $q$-axes. Consequently, it is essential to improve the existing analytical model for accurate sideband current harmonic predictions in interior PMSM drive systems with considerations of magnetic saturation and cross-coupling effects.

\section{A. Rotor Synchronous Frame}

Due to the high frequency nature, the sideband harmonic reactance will be much greater than the winding direct current resistance. Hence the sideband voltage drops over the winding resistances can be neglected. Moreover, the corresponding motional electromotive force (EMF) due to the inductance variations are very trivial and negligible. Therefore, it is justifiable to assume that the sideband voltage harmonics are all consumed by the corresponding induction EMF. By taking into account magnetic saturation and cross-coupling effects, the sideband voltage and current relation in rotor synchronous frame can be approximated as

$$
\left\{\begin{array}{l}
u_{d_{-} \omega_{k}} \simeq j \omega_{k}\left(L_{d} i_{d_{-} \omega_{k}}+M_{d q} i_{q_{-} \omega_{k}}\right) \\
u_{q_{-} \omega_{k}} \simeq j \omega_{k}\left(L_{q} i_{q_{-} \omega_{k}}+M_{d q} i_{d_{-} \omega_{k}}\right)
\end{array}\right.
$$

where the $d$-axis and $q$-axis incremental inductances and incremental mutual inductance between $d$ - and $q$-axes are 
current dependent, and they can be derived as

$$
\left\{\begin{array}{l}
L_{d}=\frac{\partial \psi_{d}\left(i_{d}, i_{q}\right)}{\partial i_{d}}, L_{q}=\frac{\partial \psi_{q}\left(i_{d}, i_{q}\right)}{\partial i_{q}} \\
M_{d q}=\frac{\partial \psi_{d}\left(i_{d}, i_{q}\right)}{\partial i_{q}}=\frac{\partial \psi_{q}\left(i_{d}, i_{q}\right)}{\partial i_{d}}
\end{array}\right.
$$

These incremental inductance parameters could be obtained from nonlinear finite element analysis (FEA) of the machine with different $d$-axis and $q$-axis currents. Nonlinear FEA sweeping can be carried out with different $i_{d}, i_{q}$, and rotor positions and the corresponding $d$-axis and $q$-axis flux linkages can be obtained accordingly. As a result, two four-dimensional (4-D) flux linkage tables are derived and the corresponding incremental inductances can be attained as three 4-D tables by implementing numerical current-partial differential operations on the flux linkage tables. Since the sideband current harmonic prediction is for steady state conditions in this paper, three three-dimensional(3-D)inductance tables can be obtained by taking average over the rotor positions for the proposed analytical model. Normally, the mutual one can also be defined as

$$
M_{d q}=\sigma_{M} \sqrt{L_{d} L_{q}}
$$

By rearranging (8), the sideband current harmonics could be presented as

$$
\left\{\begin{array}{l}
i_{d_{-} \omega_{k}}=\frac{L_{q} u_{d \_\omega_{k}}-M_{d q} u_{q_{-} \omega_{k}}}{j \omega_{k}\left(L_{d} L_{q}-M_{d q}^{2}\right)} \\
i_{q_{\_} \omega_{k}}=\frac{L_{d} u_{q_{-} \omega_{k}}-M_{d q} u_{d \_\omega_{k}}}{j \omega_{k}\left(L_{d} L_{q}-M_{d q}^{2}\right)}
\end{array}\right.
$$

The main sideband current harmonic components nearby the first and second carrier frequency can be derived by substituting the respective voltage models (1), (2), and (3) into equation (11) as

$$
\begin{aligned}
& \left\{\begin{array}{l}
i_{d_{-}\left(\omega_{s} \pm 3 \omega_{e}\right)}=\frac{U_{d c} U_{d \_13}^{\prime} \sin \left(\left(\omega_{s} \pm 3 \omega_{e}\right) t \pm \varphi_{d \_13}^{\prime}\right)}{2\left(\omega_{s} \pm 3 \omega_{e}\right) L_{d}} \\
i_{q_{\_}\left(\omega_{s} \pm 3 \omega_{e}\right)}=\frac{\mp U_{d c} U_{q_{-} 13}^{\prime} \cos \left(\left(\omega_{s} \pm 3 \omega_{e}\right) t \pm \varphi_{q_{\_} 13}^{\prime}\right)}{2\left(\omega_{s} \pm 3 \omega_{e}\right) L_{q}}
\end{array}\right. \\
& \left\{\begin{array}{l}
i_{d \_\left(2 \omega_{s}\right)}=\frac{-U_{d c} C_{21}\left(L_{q} \sin \delta+M_{d q} \cos \delta\right) \sin \left(2 \omega_{s} t\right)}{2 \omega_{s}\left(L_{d} L_{q}-M_{d q}^{2}\right)} \\
i_{q_{-}\left(2 \omega_{s}\right)}=\frac{U_{d c} C_{21}\left(L_{d} \cos \delta+M_{d q} \sin \delta\right) \sin \left(2 \omega_{s} t\right)}{2 \omega_{s}\left(L_{d} L_{q}-M_{d q}^{2}\right)}
\end{array}\right.
\end{aligned}
$$

$$
\left\{\begin{array}{l}
i_{d_{-}\left(2 \omega_{s} \pm 6 \omega_{e}\right)}=\frac{U_{d c} U_{d \_26}^{\prime} \sin \left(\left(2 \omega_{s} \pm 6 \omega_{e}\right) t \pm \varphi_{d \_26}^{\prime}\right)}{2\left(2 \omega_{s} \pm 6 \omega_{e}\right) L_{d}} \\
i_{q_{\_}\left(2 \omega_{s} \pm 6 \omega_{e}\right)}=\frac{\mp U_{d c} U_{q_{\_} 26}^{\prime} \cos \left(\left(2 \omega_{s} \pm 6 \omega_{e}\right) t \pm \varphi_{q_{\_} 26}^{\prime}\right)}{2\left(2 \omega_{s} \pm 6 \omega_{e}\right) L_{q}}
\end{array}\right.
$$

where the coefficients $U_{d \_13}^{\prime}, U_{q_{\_} 13}^{\prime}, U_{d \_26}^{\prime}$, and $U_{q_{\_} 26}^{\prime}$ can be expressed as

$$
\begin{aligned}
& U_{d_{-} 13}^{\prime}=\frac{\sqrt{U_{d_{-} 13}^{2}+C_{m d_{-} 13}}}{\left(1-\sigma_{M}^{2}\right)}, U_{q_{-} 13}^{\prime}=\frac{\sqrt{U_{q_{-} 13}^{2}+C_{m q_{-} 13}}}{\left(1-\sigma_{M}^{2}\right)} \\
& U_{d_{-} 26}^{\prime}=\frac{\sqrt{U_{d_{-} 26}^{2}+C_{m d_{-} 26}}}{\left(1-\sigma_{M}^{2}\right)}, U_{q_{-} 26}^{\prime}=\frac{\sqrt{U_{q_{-} 26}^{2}+C_{m q_{-} 26}}}{\left(1-\sigma_{M}^{2}\right)}
\end{aligned}
$$

and the initial phase angles $\varphi_{d \_13}^{\prime}, \varphi_{q_{-} 13}^{\prime}, \varphi_{d \_26}^{\prime}$, and $\varphi_{q_{\_} 26}^{\prime}$ can be determined by

$$
\begin{aligned}
& \left\{\begin{array}{l}
\cos \varphi_{d \_13}^{\prime}=\frac{\left(C_{12}+C_{14}\right)\left(M_{d q} \sin \delta-L_{q} \cos \delta\right)}{\sqrt{L_{q}^{2}\left(U_{d \_13}^{2}+C_{m d_{-} 13}\right)}} \\
\sin \varphi_{d_{-} 13}^{\prime}=\frac{\left(C_{12}-C_{14}\right)\left(M_{d q} \cos \delta+L_{q} \sin \delta\right)}{\sqrt{L_{q}^{2}\left(U_{d \_13}^{2}+C_{m d_{\_} 13}\right)}} \\
\cos \varphi_{q_{-} 13}^{\prime}=\frac{\left(C_{12}-C_{14}\right)\left(M_{d q} \sin \delta+L_{d} \cos \delta\right)}{\sqrt{L_{d}^{2}\left(U_{q_{-} 13}^{2}+C_{m q_{-} 13}\right)}} \\
\sin \varphi_{q_{-} 13}^{\prime}=\frac{\left(C_{12}+C_{14}\right)\left(M_{d q} \cos \delta-L_{d} \sin \delta\right)}{\sqrt{L_{d}^{2}\left(U_{q_{-} 13}^{2}+C_{m q_{-} 13}\right)}}
\end{array}\right. \\
& \int \cos \varphi_{d \_26}^{\prime}=\frac{\left(C_{25}-C_{27}\right)\left(L_{q} \sin \delta+M_{d q} \cos \delta\right)}{\sqrt{L_{q}^{2}\left(U_{d \_26}^{2}+C_{m d \_26}\right)}} \\
& \begin{array}{l}
\sin \varphi_{d \_26}^{\prime}=\frac{\left(C_{25}+C_{27}\right)\left(L_{q} \cos \delta-M_{d q} \sin \delta\right)}{\sqrt{L_{q}^{2}\left(U_{d \_26}^{2}+C_{m d \_26}\right)}} \\
\cos \varphi_{q_{\_} 26}^{\prime}=\frac{\left(C_{27}+C_{25}\right)\left(M_{d q} \cos \delta-L_{d} \sin \delta\right)}{\sqrt{L_{d}^{2}\left(U_{q \_26}^{2}+C_{m q \_26}\right)}}
\end{array} \\
& \sin \varphi_{q_{\_} 26}^{\prime}=\frac{\left(C_{27}-C_{25}\right)\left(M_{d q} \sin \delta+L_{d} \cos \delta\right)}{\sqrt{L_{d}^{2}\left(U_{q_{\_} 26}^{2}+C_{m q_{\_} 26}\right)}}
\end{aligned}
$$

where, $C_{m d_{-} 13}, C_{m q \_13}, C_{m d \_26}$, and $C_{m q \_26}$ are the components caused by the coupling factor, and can be determined by

$$
\begin{aligned}
& \left\{\begin{array}{l}
C_{m{ }_{-13}}=\frac{M_{d q}^{2} U_{q \_13}^{2}-4 C_{12} C_{14} M_{d q} L_{q} \sin (2 \delta)}{L_{q}^{2}} \\
C_{m q_{\_} 13}=\frac{M_{d q}^{2} U_{d \_13}^{2}-4 C_{12} C_{14} M_{d q} L_{d} \sin (2 \delta)}{L_{d}^{2}}
\end{array}\right. \\
& \left\{\begin{array}{l}
C_{m d \_26}=\frac{M_{d q}^{2} U_{q \_26}^{2}-4 C_{25} C_{27} M_{d q} L_{q} \sin (2 \delta)}{L_{q}^{2}} \\
C_{m q \_26}=\frac{M_{d q}^{2} U_{d \_26}^{2}-4 C_{25} C_{27} M_{d q} L_{d} \sin (2 \delta)}{L_{d}^{2}}
\end{array}\right.
\end{aligned}
$$

\section{B. Stator Stationary Frame}

The $\left(\omega_{s} \pm 3 \omega_{e}\right)-,\left(2 \omega_{s}\right)-$, and $\left(2 \omega_{s} \pm 6 \omega_{e}\right)$-order sideband current harmonics in the rotor synchronous frame from (12)(14) can be converted into $\left(\omega_{s} \pm 2 \omega_{e}\right)$ - and $\left(\omega_{s} \pm 4 \omega_{e}\right)-,\left(2 \omega_{s} \pm\right.$ $\left.\omega_{e}\right)$-, and $\left(2 \omega_{s} \pm 5 \omega_{e}\right)$ - and $\left(2 \omega_{s} \pm 7 \omega_{e}\right)$-order ones in stator 


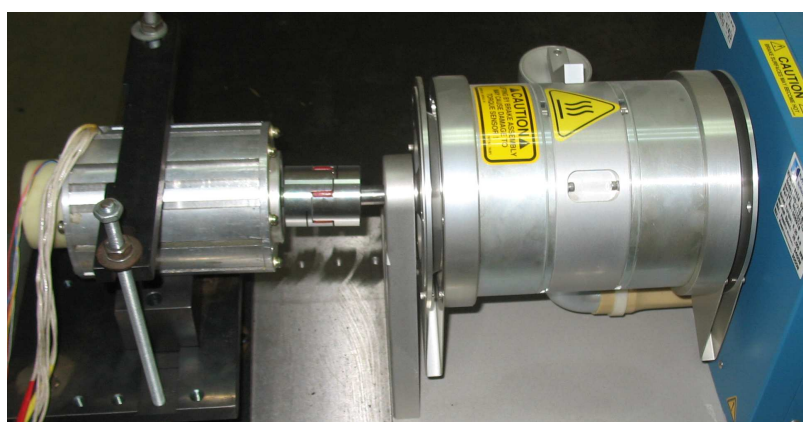

Fig. 1. Experimental setup of the prototype interior PMSM drive system

phase current. The respective amplitudes of those harmonics in the stator stationary frame can be accordingly derived as

$$
\begin{gathered}
\left\{\begin{array}{l}
i_{s_{-}\left(\omega_{s} \pm 2 \omega_{e}\right)}=\frac{U_{d c} \sqrt{M_{2}^{2}+N_{1}^{2}+2 M_{2} N_{1} \cos (2 \delta)+R_{12}}}{4\left(\omega_{s} \pm 3 \omega_{e}\right)\left(1-\sigma_{M}^{2}\right)} \\
i_{s_{-}\left(\omega_{s} \pm 4 \omega_{e}\right)}=\frac{U_{d c} \sqrt{M_{1}^{2}+N_{2}^{2}+2 M_{1} N_{2} \cos (2 \delta)+R_{14}}}{4\left(\omega_{s} \pm 3 \omega_{e}\right)\left(1-\sigma_{M}^{2}\right)}
\end{array}\right. \\
i_{s_{-}\left(2 \omega_{s} \pm \omega_{e}\right)}=\frac{U_{d c} C_{21}}{4 \omega_{s}\left(1-\sigma_{M}^{2}\right)} \sqrt{\frac{\sin ^{2} \delta}{L_{d}^{2}}+\frac{\cos ^{2} \delta}{L_{q}^{2}}+R_{21}}
\end{gathered}
$$

$$
\left\{\begin{array}{l}
i_{s_{-}\left(2 \omega_{s} \pm 5 \omega_{e}\right)}=\frac{U_{d c} \sqrt{M_{4}^{2}+N_{3}^{2}+2 M_{4} N_{3} \cos (2 \delta)+R_{25}}}{4\left(2 \omega_{s} \pm 6 \omega_{e}\right)\left(1-\sigma_{M}^{2}\right)} \\
i_{s_{-}\left(2 \omega_{s} \pm 7 \omega_{e}\right)}=\frac{U_{d c} \sqrt{M_{3}^{2}+N_{4}^{2}+2 M_{3} N_{4} \cos (2 \delta)+R_{27}}}{4\left(2 \omega_{s} \pm 6 \omega_{e}\right)\left(1-\sigma_{M}^{2}\right)}
\end{array}\right.
$$

where $R_{12}, R_{14}, R_{21}, R_{25}$, and $R_{27}$ can be obtained as

$$
\left\{\begin{array}{l}
R_{12}=\frac{4 \sigma_{M}^{2} C_{14}^{2}}{L_{d} L_{q}}-\frac{4 M_{2} M_{d q} C_{14}}{L_{d} L_{q}} \sin (2 \delta) \\
R_{14}=\frac{4 \sigma_{M}^{2} C_{12}^{2}}{L_{d} L_{q}}-\frac{4 N_{2} M_{d q} C_{12}}{L_{d} L_{q}} \sin (2 \delta) \\
R_{21}=\frac{\sigma_{M}^{2}}{L_{d} L_{q}}+\left(\frac{1}{L_{d}}+\frac{1}{L_{q}}\right) \frac{M_{d q}}{L_{d} L_{q}} \sin (2 \delta) \\
R_{25}=\frac{4 \sigma_{M}^{2} C_{27}^{2}}{L_{d} L_{q}}-\frac{4 M_{4} M_{d q} C_{27}}{L_{d} L_{q}} \sin (2 \delta) \\
R_{27}=\frac{4 \sigma_{M}^{2} C_{25}^{2}}{L_{d} L_{q}}-\frac{4 N_{4} M_{d q} C_{25}}{L_{d} L_{q}} \sin (2 \delta)
\end{array}\right.
$$

and $M_{1}-M_{4}, N_{1}-N_{4}$ are given by

$$
\begin{cases}M_{1}=\frac{C_{12}}{L_{d}}-\frac{C_{12}}{L_{q}}, & M_{2}=\frac{C_{12}}{L_{d}}+\frac{C_{12}}{L_{q}} \\ M_{3}=\frac{C_{25}}{L_{d}}-\frac{C_{25}}{L_{q}}, & M_{4}=\frac{C_{25}}{L_{d}}+\frac{C_{25}}{L_{q}} \\ N_{1}=\frac{C_{14}}{L_{d}}-\frac{C_{14}}{L_{q}}, & N_{2}=\frac{C_{14}}{L_{d}}+\frac{C_{14}}{L_{q}} \\ N_{3}=\frac{C_{27}}{L_{d}}-\frac{C_{27}}{L_{q}}, & N_{4}=\frac{C_{27}}{L_{d}}+\frac{C_{27}}{L_{q}}\end{cases}
$$

TABLE I

Key Design Parameters of the Machine

\begin{tabular}{|c|c|c|c|}
\hline Machine Parameter & Value & Machine Parameter & Value \\
\hline Phase number & 3 & Pole number & 10 \\
\hline Stator outer diameter & $76 \mathrm{~mm}$ & Axial active length & $70 \mathrm{~mm}$ \\
\hline DC link voltage & $42 \mathrm{~V}$ & PWM frequency & $4 \mathrm{kHz}$ \\
\hline Phase resistance & $0.5 \Omega$ & PM flux linkage & $0.048 \mathrm{~Wb}$ \\
\hline Rated speed & $300 \mathrm{rpm}$ & Maximum Torque & $5.5 \mathrm{Nm}$ \\
\hline
\end{tabular}

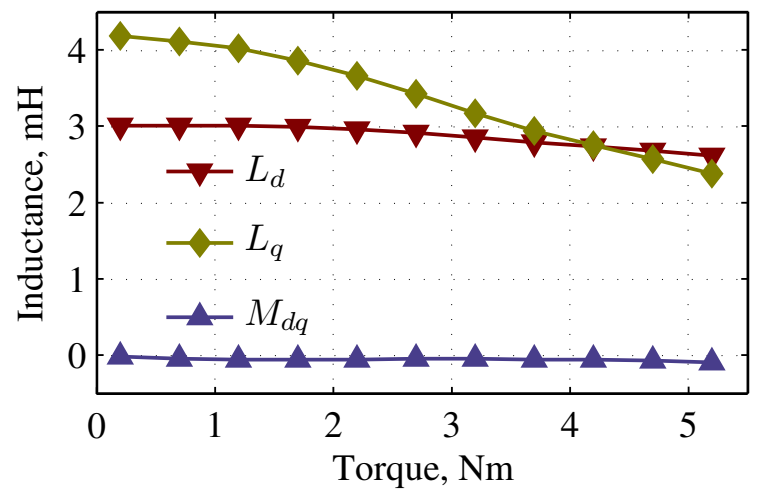

(a)

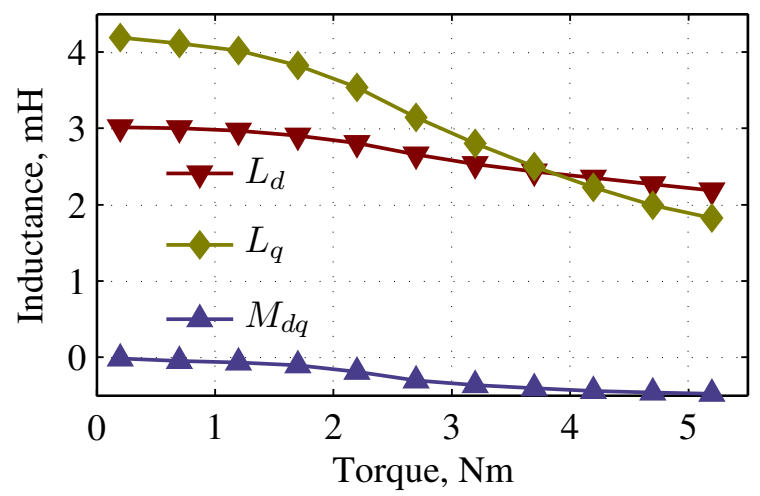

(b)

Fig. 2. The incremental inductance parameters under different operational condition: (a) MTPA vector control; (b) $i_{d}=0$ vector control.

\section{EXPERIMENTAL VALIDATIONS}

\section{A. Experimental Interior PMSM Drive System}

The experimental tests on a prototype interior PMSM drive system under different control strategies and load conditions are comprehensively carried out in order to validate the accuracy improvements on the main sideband current harmonic predictions of the proposed method over the existing one. The actual experimental setup of the proposed interior PMSM drive testing systems is depicted in Fig.1, while the main parameters of the drive are given in Table I. For the experimental validations, the prototype machine is driven by a common two-level VSI with SVPWM technique under both $i_{d}=0$ and maximum torque per ampere (MPTA) control algorithms.

The nonlinear FEA models are employed to obtain the corresponding incremental inductance parameters for the improved model in order to account for the magnetic saturation and cross-coupling effects under different operational con- 


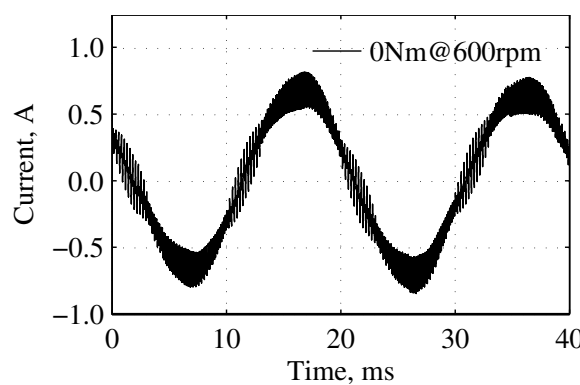

(a)

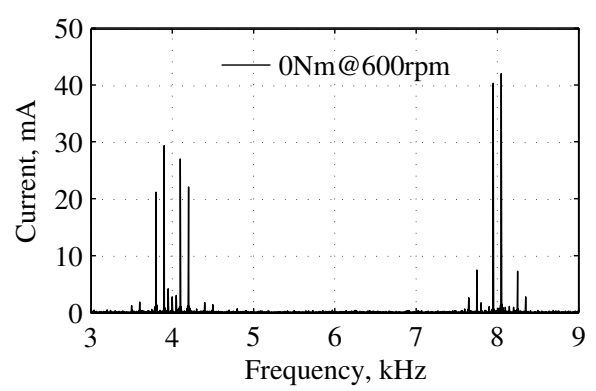

(d)

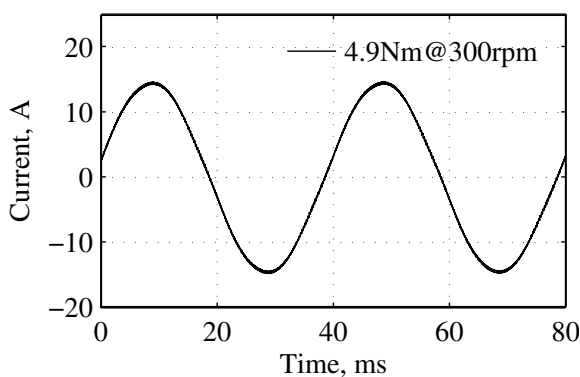

(b)

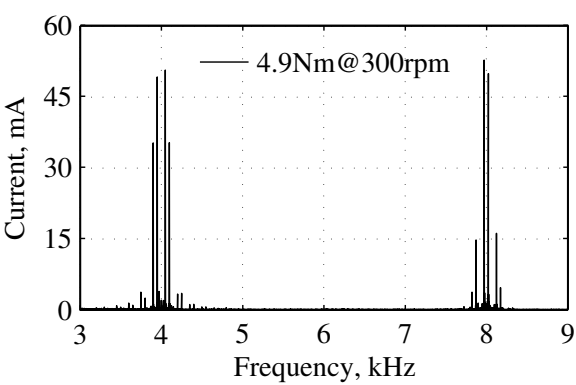

(e)

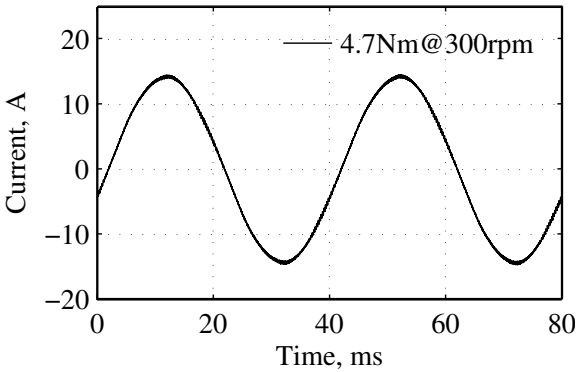

(c)

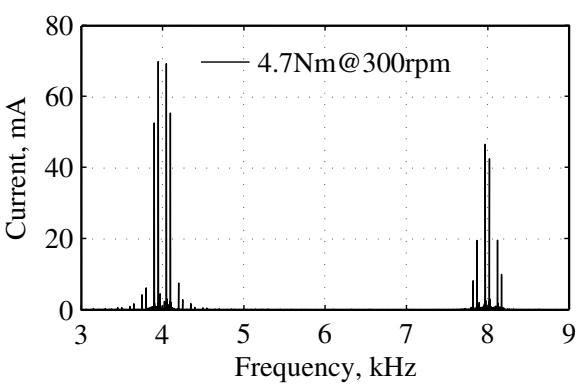

(f)

Fig. 3. Experimental phase current waveforms and their harmonic spectra under different conditions, (a) Current waveform under no load operation; (b) Current waveform under MTPA control; (c) Current waveform under $i_{d}=0$ control; (d) Current spectrum under no load operation; (e) Current spectrum under MTPA control; (f) Current spectrum under $i_{d}=0$ control.

ditions. Although the incremental inductance parameters are dependent on not only stator currents but also rotor positions, the variations for different rotor positions are relatively small in practice. Without loss of generality, the incremental inductance values in this paper are calculated with $i_{d}$ ranged from -10 to $0 \mathrm{~A}$ and $i_{q}$ ranged from 0 to $18 \mathrm{~A}$ under only one particular rotor position which aligns the $d$-axis with one stator phase winding in order to significantly reduce the computational time. 50 current steps are taken for both $i_{d}$ and $i_{q}$ so that the computational errors for the numerical partial differential operations can be minimized. As a result, three 3-D tables for incremental inductances are obtained for the proposed prototype. With the corresponding $i_{d}$ and $i_{q}$ in torque-current characteristics curves from MTPA and $i_{d}=0$ control strategies, the resultant inductance-torque curves can be compiled from the 3-D incremental inductance tables and illustrated in Fig.2(a) and Fig.2(b), respectively. It can be easily observed from the figures that $d$ - and $q$-axes incremental inductances will decrease as the output torque rises under both control algorithms due to the aggravating magnetic saturation in the machine. Since the demagnetizing currents generated by the MTPA control can prevent the prototype from magnetic saturation to some extent, the corresponding inductances for $i_{d}=0$ control will decline much faster than the ones for MTPA control. And for the same reason, the cross-couple effects, which can be represented by the mutual inductance between $d$ - and $q$-axes, barely occur under MPTA operations, but can reach quite noticeable level under $i_{d}=0$ operations. Generally, $i_{d}=0$ operations will result in smaller inductance parameters as shown in Fig.2, which implies that more severe sideband current harmonics can be expected.
The phase current waveforms and relevant sideband harmonic spectrum of the prototype interior PMSM under no load at $600 \mathrm{rpm}, 4.9 \mathrm{~N} \cdot \mathrm{m}$ load at $300 \mathrm{rpm}$ with MTPA control, and $4.7 \mathrm{~N} \cdot \mathrm{m}$ load at $300 \mathrm{rpm}$ with $i_{d}=0$ control from experimental tests are captured and illustrated in Fig.3. With a gentle contribution from the reluctance torque, larger overall torque output has been realized in the machine with MTPA control with the same current amplitude as shown in Fig.3(b) and Fig.3(c). From figures, it is well validated that the $\left(\omega_{s} \pm 2 \omega_{e}\right)-,\left(\omega_{s} \pm 4 \omega_{e}\right)$-, and $\left(2 \omega_{s} \pm \omega_{e}\right)$-order components are the major components for the sideband current harmonics nearby the first and second carrier frequency. In addition, there are also noticeable $\left(2 \omega_{s} \pm 5 \omega_{e}\right)$ - and $\left(2 \omega_{s} \pm 7 \omega_{e}\right)$-order harmonics in the second carrier frequency domain. However, the amplitudes of these current harmonics are relatively small and usually can be neglected except under large modulation index conditions. As expected, the $\left(\omega_{s} \pm 2 \omega_{e}\right)$ - and $\left(\omega_{s} \pm 4 \omega_{e}\right)$ order components in the machine with $i_{d}=0$ control is much more significant than the ones with MTPA control due to corresponding more severe magnetic saturation.

\section{B. Experimental Validations under Different Loads}

The experiment tests of the prototype interior PMSM with varios load conditions are carried out to quantitatively validate the proposed improved model. First, the experimental tests of the machine with no load conditions at different speed ranged from 0 to $900 \mathrm{rpm}$ are comprehensively conducted and the resultant current characteristics are captured and stored. The $\left(\omega_{s} \pm 2 \omega_{e}\right)$ - and $\left(\omega_{s} \pm 4 \omega_{e}\right)$-order components in first carrier frequency domain and $\left(2 \omega_{s} \pm \omega_{e}\right)-,\left(2 \omega_{s} \pm 5 \omega_{e}\right)-$, and $\left(2 \omega_{s} \pm 7 \omega_{e}\right)$-order ones in second carrier frequency domain 


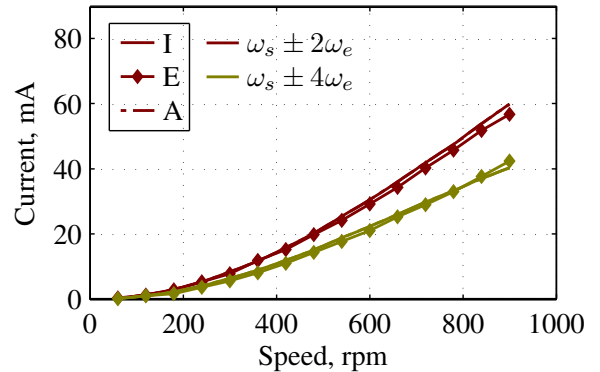

(a)

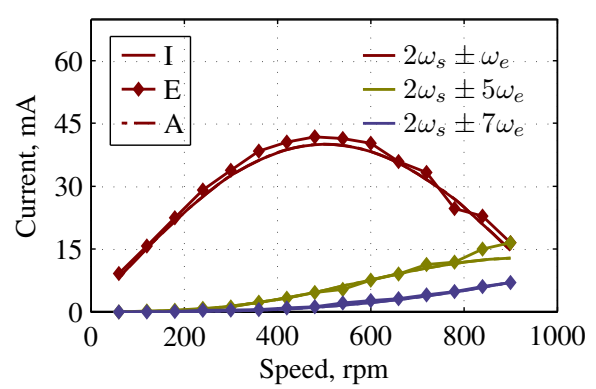

(d)

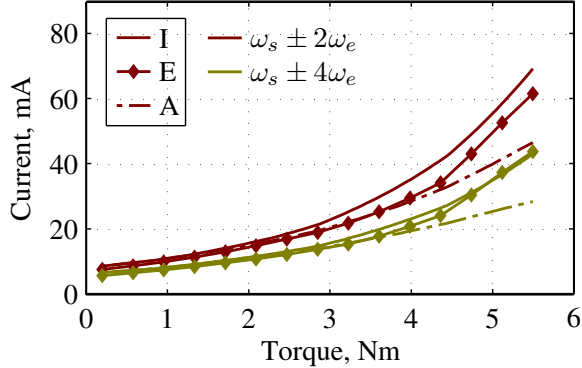

(b)

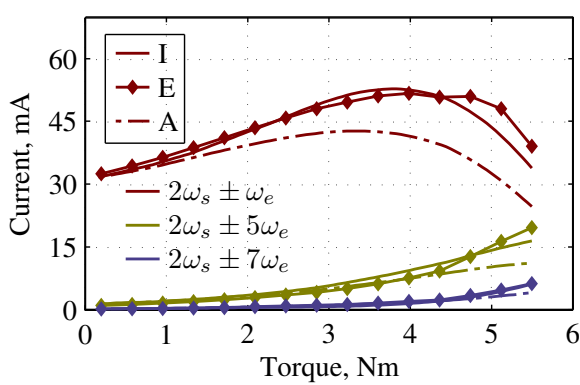

(e)

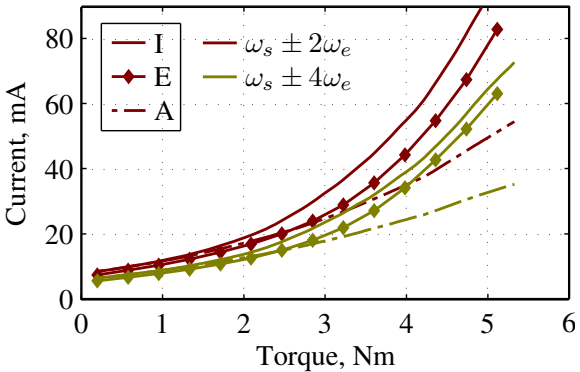

(c)

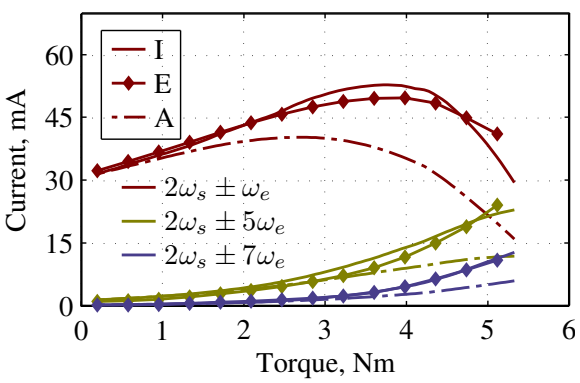

(f)

Fig. 4. Sideband harmonics under different operational conditions, (a) First order components under no load operations; (b) First order components under MTPA control; (c) First order components under $i_{d}=0$ control; (d) Second order components under no load operations; (e) Second order components under MTPA control; (f) Second order components under $i_{d}=0$ control.(I-improved analytical model; E-Experimental results; A-Existing analytical model)

are derived based on the stored current information, complied accordingly, and given in Fig.4(a) and Fig.4(d). The figures demonstrate excellent agreements between experimental and estimated results have been achieved. Moreover, the results from the existing and proposed improved analytical models generally coincide in the figures as the $L_{d}$, and $L_{q}$ can be considered to be constant with no load operation with different speed, and $M_{d q}$ is also negligible.

Nevertheless, the neglect of magnetic saturation and crosscouple effects in the analytical model can potentially lead to large error in the prototype interior PMSM under load conditions. The main sideband current harmonics of the machine under different load conditions with MTPA control are heavily affected by the corresponding magnetic saturation. Consequently, large deviations between the results from the existing analytical model and experimental tests are revealed in Fig.4(b) and Fig.4(e), especially under large load conditions. The incremental inductance parameters used in the existing analytical model are linear and generally larger than the actual ones, hence analytical results are well underestimated. On the other hand, the discrepancies between the results from the proposed improved model and experiment results have been effectively mitigated for all the first and second order sideband current harmonic components. The prediction accuracies have been significantly improved particularly for the $\left(\omega_{s} \pm 2 \omega_{e}\right)-,\left(\omega_{s} \pm 4 \omega_{e}\right)$ - and $\left(2 \omega_{s} \pm \omega_{e}\right)$-order ones. The remaining small errors are primarily caused by the errors on the incremental inductance parameter evaluations as well as the experimental measurement errors. Generally, B-H characteristics of the lamination material in FEA models cover only up to $2.0 \mathrm{~T}$, and empirical formula based on curve fitting is employed to approximate the region beyond that value. The magnetic flux density of pole shoes of the prototype interior PMSM under heavy load conditions can well exceed that value, thus potential estimation errors can be expected. The resistance variations caused by the temperature rise during the experimental tests can result in corresponding voltage drop changes on the circuit and hence induce errors. Furthermore, the incremental inductances of the prototype machine depend on not only the stator currents but also rotor positions. The inductance values used for the analytical methods in this paper are derived from one particular rotor position in order to reduce the computational efforts. This simplification will also introduce some errors to the predicted results. On the whole, the estimation accuracy has been significantly ameliorated by the proposed improved model over the existing analytical one.

Furthermore, more distinct errors between the results from existing analytical model and experimental tests exists in the machine under heavy load conditions with $i_{d}=0$ vector control, for all five sideband current harmonic components as demonstrated in Fig.4(c) and Fig.4(f). This is due to the more severe incremental inductance decline and extra influences from the cross-couple effects from machine with $i_{d}=0$ vector control. Consequently, the $\left(\omega_{s} \pm 2 \omega_{e}\right)-,\left(\omega_{s} \pm 4 \omega_{e}\right)-$, $\left(2 \omega_{s} \pm 5 \omega_{e}\right)$ - and $\left(2 \omega_{s} \pm 7 \omega_{e}\right)$-order sideband current harmonics in the machine with $i_{d}=0$ control are much larger than the ones with MTPA control under the same load conditions, as expected. However, the $\left(2 \omega_{s} \pm \omega_{e}\right)$-order ones are very similar for both control algorithms. As the sharp current incline under heavy load conditions will result in large winding voltage drop, the associated modulation index will be significantly increased. On the other side, the $\left(2 \omega_{s} \pm \omega_{e}\right)$-order sideband 
components will start to decrease as the modulation index reaches up to around 0.619 [24]. When the modulation index exceeds that particular value under heavy load conditions, the $\left(2 \omega_{s} \pm \omega_{e}\right)$-order sideband current harmonics will decline rapidly and the impacts of the magnetic saturation and crosscoupling effects will gradually diminish. Under the conditions of light output torque, the incremental inductance parameters of the machine with both control algorithms are quite close, seen from Fig.2. the slightly smaller inductance values with $i_{d}=0$ control, together with slightly larger power angles with MTPA control, eventually make the $\left(2 \omega_{s} \pm \omega_{e}\right)$ sideband current harmonics of the test drive with both control algorithms have the similar values. The resultant errors between the results from the improved model and experimental tests are somewhat satisfactory, particularly the trend of all major sideband harmonic components under extreme conditions have been accurately reflected.

\section{CONCLUSION}

By taking into account the magnetic saturation and crosscoupling effects, an improved analytical model for sideband current harmonic components in interior PMSM powered by two-level VSI with regular sampled SVPWM technique has been proposed and developed in this paper. Instead of constant machine inductance, the nonlinear characteristics of incremental inductances $L_{d}$ and $L_{q}$ and mutual incremental inductance $M_{d q}$ in the machines are incorporated into the proposed analytical formulae in order to effectively improve the estimation accuracy. The improved model suggests that the existing analytical method based on constant inductance values tends to underestimate the sideband current harmonic components.

The incremental inductance results of a prototype interior PMSM from nonlinear FEA evaluations reveal that they are highly dependent on not only the load conditions but also the control strategies. Furthermore, the experimental tests on this particular prototype drive with different load conditions and control algorithms strategies have been carried out for comprehensive validations. The direct comparisons of the results from the existing and improved analytical models, and experimental tests have shown a significant accuracy improvement on the predictions from the proposed analytical method. Therefore, it is practically very necessary to employ the proposed analytical method for interior PMSM drives in order to avoid large errors in the predictions of the sideband current harmonics. Furthermore, the results from MTPA and $i_{d}=0$ vector controls have revealed the impacts of control strategies on the sideband current harmonics. The proposed model can offer a very detailed and insightful revelation of impacts of the magnetic saturation and cross-coupling effects. Moreover, the proposed method can promptly evaluate the influences of control strategy on the sideband current harmonics over the existing analytical method.

\section{APPENDIX}

The parameters $C_{12}, C_{14}, C_{21}, C_{25}$, and $C_{27}$ in equations (1)-(5) are determined by

$$
\left\{\begin{aligned}
C_{12}= & \frac{4}{\pi}\left(J_{2}\left(\frac{M \pi}{2}\right) J_{0}\left(\frac{M \pi \xi}{2}\right)-J_{1}\left(\frac{M \pi}{2}\right) J_{1}\left(\frac{M \pi \xi}{2}\right)\right) \\
C_{14}= & \frac{4}{\pi} J_{1}\left(\frac{M \pi}{2}\right) J_{1}\left(\frac{M \pi \xi}{2}\right) \\
C_{21}= & -\frac{2}{\pi}\left(J_{1}(M \pi) J_{0}(M \pi \xi)+J_{2}(M \pi) J_{1}(M \pi \xi)\right. \\
& \left.-J_{4}(M \pi) J_{1}(M \pi \xi)\right) \\
C_{25}= & -\frac{2}{\pi} J_{2}(M \pi) J_{1}(M \pi \xi) \\
C_{27}= & -\frac{2}{\pi} J_{4}(M \pi) J_{1}(M \pi \xi) .
\end{aligned}\right.
$$

where

$$
\xi=\frac{3 \sqrt{3}}{8 \pi}
$$

and the $k^{t h}$ order Bessel formula can be expressed as

$$
J_{k}(x)=\sum_{n=0}^{\infty} \frac{(-1)^{n}}{n !} \frac{1}{\Gamma(k+n+1)}\left(\frac{x}{2}\right)^{2 n+k}
$$

where

$$
\Gamma(k+n+1)=(k+n) !
$$

\section{REFERENCES}

[1] T. M. Jahns and V. Blasko, "Recent advances in power electronics technology for industrial and traction machine drives," Proc. IEEE, vol. 89, no. 6, pp. 963-975, Jun 2001.

[2] A. M. EL-Refaie, "Fractional-slot concentrated-windings synchronous permanent magnet machines: Opportunities and challenges," IEEE Trans. Ind. Electron., vol. 57, no. 1, pp. 107-121, Jan. 2010.

[3] D. G. Dorrell, M. Hsieh, M. Popescu, L. Evans, D. A. Staton, and V. Grout, "A review of the design issues and techniques for radialflux brushless surface and internal rare-earth permanent-magnet motors," IEEE Trans. Ind. Electron., vol. 58, no. 9, pp. 3741-3757, Sep. 2011.

[4] A. Boglietti, P. Ferraris, M. Lazzari, and M. Pastorelli, "Influence of the inverter characteristics on the iron losses in pwm inverter-fed induction motors," IEEE Trans. Ind. Appl., vol. 32, no. 5, pp. 1190-1194, Sep./Oct. 1996.

[5] S. Khomfoi, V. Kinnares, and P. Viriya, "Influence of pwm characteristics on the core losses due to harmonic voltages in pwm fed induction motors," in Proc. IEEE Power Eng. Soc. Winter Meeting, vol. 1, 2000, pp. 365-369 vol.1.

[6] P. Hothongkham and V. Kinnares, "Investigation into harmonic losses in a pwm multilevel cascaded h-bridge inverter fed induction motor," in Proc. Int. Power Electron. Drive Syst. Conf., Nov. 2007, pp. 1043-1048.

[7] K. Basu, J. S. Siva Prasad, and G. Narayanan, "Minimization of torque ripple in pwm ac drives," IEEE Trans. Ind. Electron., vol. 56, no. 2, pp. 553-558, Feb. 2009.

[8] S. Halasz and Z. Kohari, "Torque pulsations of multiphase inverter-fed ac motors," in Proc. Int. Power Electron. Motion Control Conf., Sep. 2010, pp. 157-162.

[9] A. K. Wallace, R. Spee, and L. G. Martin, "Current harmonics and acoustic noise in ac adjustable-speed drives," IEEE Trans. Ind. Appl., vol. 26, no. 2, pp. 267-273, Mar./Apr. 1990.

[10] J. Le Besnerais, V. Lanfranchi, M. Hecquet, and P. Brochet, "Characterization and reduction of audible magnetic noise due to pwm supply in induction machines," IEEE Trans. Ind. Electron., vol. 57, no. 4, pp. 1288-1295, Apr. 2010.

[11] J. T. Boys and P. G. Handley, "Harmonic analysis of space vector modulated pwm waveforms," IEE Proc. Electric Power Appl., vol. 137, no. 4, pp. 197-204, Jul. 1990. 
[12] J. F. Moynihan, M. G. Egan, and J. M. D. Murphy, "Theoretical spectra of space-vector-modulated waveforms," IEE Proc. Electric Power Appl., vol. 145 , no. 1 , pp. 17-24, Jan. 1998.

[13] D. G. Holmes, "A general analytical method for determining the theoretical harmonic components of carrier based pwm strategies," in Proc. IEEE Ind. Appl. Soc. Annu. Meeting, vol. 2, Oct. 1998, pp. 12071214 vol.2.

[14] A. W. Leedy and R. M. Nelms, "Harmonic analysis of a space vector pwm inverter using the method of multiple pulses," in Proc. IEEE Int. Symp. Ind. Electron., vol. 2, Jul. 2006, pp. 1182-1187.

[15] H. W. van der Broeck, H. C. Skudelny, and G. V. Stanke, "Analysis and realization of a pulsewidth modulator based on voltage space vectors," IEEE Trans. Ind. Appl., vol. 24, no. 1, pp. 142-150, Jan./Feb. 1988.

[16] T. A. Sakharuk, A. M. Stankovic, G. Tadmor, and G. Eirea, "Modeling of pwm inverter-supplied ac drives at low switching frequencies," IEEE Trans. Circuits Syst. I, vol. 49, no. 5, pp. 621-631, May 2002.

[17] S. Halasz, G. Csonka, and A. A. H. Hassan, "Generalized harmonic loss curves of ac motors fed from two and three level inverters," in Proc. IEEE Ind. Electron. Soc. Annu. Conf., vol. 2, Aug. 1996, pp. 957-962 vol.2.

[18] G. Narayanan and V. T. Ranganathan, "Analytical evaluation of harmonic distortion in pwm ac drives using the notion of stator flux ripple," IEEE Trans. Power Electron., vol. 20, no. 2, pp. 466-474, Mar. 2005.

[19] B. P. McGrath, D. G. Holmes, and T. Meynard, "Reduced pwm harmonic distortion for multilevel inverters operating over a wide modulation range," IEEE Trans. Power Electron., vol. 21, no. 4, pp. 941-949, Jul. 2006.

[20] G. Narayanan, V. T. Ranganathan, D. Zhao, H. K. Krishnamurthy, and R. Ayyanar, "Space vector based hybrid pwm techniques for reduced current ripple," IEEE Trans. Ind. Electron., vol. 55, no. 4, pp. 16141627, Apr. 2008.

[21] D. W. Kang and D. S. Hyun, "Simple harmonic analysis method for multi-carrier pwm techniques using output phase voltage in multi-level inverter," IEE Proc. Electric Power Appl., vol. 152, no. 2, pp. 157-165, Mar. 2005.

[22] T. Beechner and J. Sun, "Harmonic cancellation under interleaved pwm with harmonic injection," in Power Electronics Specialists Conference, 2008. PESC 2008. IEEE, Jun. 2008, pp. 1515-1521.

[23] L. Accardo, M. Fioretto, G. Giannini, and P. Marino, "Techniques of pwm space vector modulation for the reduction of magnetic acoustic noise in traction motor," in Proc. Int. Symp. Power Electron., Elect. Drives, Autom. Motion, May 2006, pp. 1084-1089.

[24] W. Liang, J. Wang, and W. Fang, "Analytical modeling of sideband current harmonic components in induction machine drive with voltage source inverter by an svm technique," IEEE Trans. Power Electron., vol. 28 , no. 11 , pp. 5372-5379, Nov. 2013.

[25] W. Liang, J. Wang, P. C.-K. Luk, W. Fang, and W. Fei, "Analytical modeling of current harmonic components in pmsm drive with voltagesource inverter by svpwm technique," IEEE Trans. Energy Convers., vol. 29, no. 3, pp. 673-680, Sep. 2014.

[26] M. A. Rahman, "History of interior permanent magnet motors [history]," IEEE Ind. Appl. Mag., vol. 19, no. 1, pp. 10-15, Jan. 2013.

[27] B. Stumberger, G. Stumberger, D. Dolinar, A. Hamler, and M. Trlep, "Evaluation of saturation and cross-magnetization effects in interior permanent-magnet synchronous motor," IEEE Trans. Ind. Appl., vol. 39, no. 5, pp. 1264-1271, Sep./Oct. 2003.

[28] P. Ponomarev, I. Petrov, and J. Pyrhonen, "Influence of travelling current linkage harmonics on inductance variation, torque ripple and sensorless capability of tooth-coil permanent-magnet synchronous machines," IEEE Trans. Magn., vol. 50, no. 1, pp. 1-8, Jan. 2014. 